\title{
Ética na pesquisa: um estudo sobre teses de doutoramento em educação
}

\author{
Jones Baroni Ferreira de Menezes ${ }^{1}$ \\ Ana Michele da Silva Lima ${ }^{2}$ \\ João Batista Carvalho Nunes ${ }^{3}$
}

\section{Resumo}

Esta pesquisa objetiva analisar teses de doutorado em um programa de pós graduação em Educação, dos anos de 2013 a 2016, referentes às questões éticas de publicações que envolvem sujeitos humanos, por meio de uma pesquisa documental de abordagem mista. Foram defendidas 92 teses no período, das quais 32 são pesquisas com seres humanos. Destas, apenas oito informam terem sido submetidas e aprovadas por um Comitê de Ética. Outras, apresentam apenas o termo de consentimento e o termo de anuência do local pesquisado. Destarte, há observância ainda tímida de regulamentação ética nos trabalhos, podendo ser reflexo da inexistência de normativa legal para a área de Ciências Humanas e Sociais, o que nos direciona para a necessidade de um marco regulatório próprio da área.

Palavras-chave: Pesquisa em Educação. Ciências Humanas e Sociais. Aspectos Éticos.

\section{Research Ethics: a study on doctoral studies in education}

\begin{abstract}
This research aims to analyze doctoral theses in a postgraduate program in Education, from the years 2013 to 2016 , referring to the ethical issues of publications involving human subjects, through a documental research with a mixed approach. 92 theses were defended in the period, of which 32 are research with human beings. Of these, only eight report having been submitted and approved by an Ethics Committee. Others present only the consent form and the consent form of the place searched. Thus, there is still a timid observance of an ethical regulation in the works, which may be a reflection of the lack of legal regulations for the area of Human and Social Sciences, which directs us to the need for a regulatory framework specific to the area.

Keywords: Education Research. Human and Social Sciences. Ethical Aspects.
\end{abstract}

\section{Introdução}

Dos atos mais simples aos mais complexos, sempre estamos perpassando-os por um controle subjetivo, conceitual e valorativo, mas permeado por regras e direitos que demonstram a legalidade e a eticidade (SEVERINO, 2014; VEATCH, 2014). Este cenário exarcerba-se com a internet e todas as possibilidades que o avanço tecnológico trouxe, frente à questão da

\footnotetext{
${ }^{1}$ Universidade Estadual do Ceará (UECE), Fortaleza - CE, jones.baroni@uece.br

2 Universidade Estadual do Ceará (UECE), Fortaleza - CE, anamichelesl@gmail.com

${ }^{3}$ Universidade Estadual do Ceará (UECE), Fortaleza - CE, joao.nunes@uece.br
} 
comunicação humana, nos proporcionando troca de informações e conhecimentos de forma imediatista, desde uma simples foto postada em um perfil de rede social à proliferação rápida de notícias falsas (fake news). Deste modo, é que a palavra ética tem ganhado, de forma periódica, grande destaque nos noticiários e nos múltiplos diálogos cotidianos da sociedade brasileira.

Tais fatos nos levam a remeter a preceitos etimológicos do vocábulo da palavra ética para compreendê-la, tanto conceitualmente quanto a contextualizar seu uso. O termo "Ética" tem origem linguística na Grécia, vindo da palavra grega ETHIKOS, que significa "aquilo que pertence ao bom costume" ou aquilo que pertence ao ETHOS (que significa "bom costume" ou "portador de caráter") e está relacionado a costumes e modos da época da Grécia antiga ${ }^{4}$.

Dentre os diversos cenários preocupados com as questões éticas, sublinhamos a área acadêmica, cuja discussão ético-moral torna-se recorrente, tanto em pautas sobre posturas, comportamentos, práticas e teorias éticas. Quanto aos pertinentes problemas com plágios, cópias e autoplágios ou pelos quesitos ligados a bons modos com sujeitos, coleta e análise dos dados, às submissões ou não a comitês de ética nas pesquisas científicas, pode-se afirmar que esses são exemplos da discussão ético-moral, recorrente no campo acadêmico, e que tornam necessária a reflexão e compreensão desse debate.

No Brasil, o desenvolvimento científico e tecnológico ocorre principalmente no meio universitário, singularmente nos cursos de Pós-Graduação. Surge em resposta a uma demanda contextual da industrialização, visando à ampliação das pesquisas, o que possibilitou, também, a expansão da universidade pública, tendo as Universidade de São Paulo e a Universidade de Brasília como pioneiras, inspiradas por organizações americanas e influenciadas por experiências europeias (CUNHA, 1986).

A mais, é uma realidade brasileira, a concentração de boa parte das pesquisas científicas nas universidades públicas, proporcionando assim grande valor a esses loci, no desenvolvimento econômico e social do País. Esse cenário ampliou-se com a criação do Conselho Nacional de Desenvolvimento Científico e Tecnológico (CNPq) e da Coordenação de Aperfeiçoamento de Pessoal de Nível Superior (CAPES), em 1951, tendo o Sul e o Sudeste brasileiro como focos das

\footnotetext{
${ }^{4}$ Gramática.net. Ética. Disponível em: https://www.gramatica.net.br/?s=\%C3\%A9tica. Acesso em 04 jul. 2017.
} 
primeiras instalações dessas instituições (GOERGEN, 2015; OLIVEIRA; FONSECA, 2010).

Deste modo, as universidades, especialmente os cursos de mestrado e doutorado, tornaram-se sítio do debate relativo ao elo entre pesquisa e ética. Para Nosella (2008), a pesquisa é fonte de produção e transmissão dos saberes nas diferentes áreas de conhecimento (ciências humanas, exatas, biológicas, da comunicação, da arte etc), estando, portanto, muitas questões éticas envolvidas na realização destas, tornando necessária discussão ampla da regulamentação sobre os princípios morais inerentes a elas.

Essa conjuntura traz consigo enorme desafio, que nos possibilita questionar o foco e os objetivos que regem a Educação em si, a Universidade e a pesquisa científica na contemporaneidade, não só no Brasil (GOERGEN, 2015). A produção de publicações com dados fabricados e ou criados sem respaldo nos levam a fatos, no mínimo, questionáveis e mesmo falsos, pontos norteadores suficientes para maior preocupação sobre: como está se propondo a pesquisa no Brasil? Em que condições, a que interesse e quem são os envolvidos? Quais possíveis consequências dessas posturas nos levam a reflexões e análises sobre ética no âmbito da pesquisa científica? (SEVERINO, 2014).

Destaca-se que o sentido ético da pesquisa é foco de preocupação de cientistas de diversas áreas, como sociólogos, filósofos, teólogos, ecologistas, futurólogos e de muitos outros intelectuais, em debate acirrado e focado em conceitos como liberdade, objetividade, sociabilidade, regulação e ética. Conforme Nosella (2008, p.255), “[...]a pesquisa transforma o problema técnico em questão ética", assim a investigação sem direcionamento ético, na verdade, configura-se sem rumo. Para melhor entendimento, Carvalho e Machado (2014, p.211) esclarecem que

a integridade na Pesquisa diz respeito à conduta do pesquisador no tratamento dos dados e na publicação da pesquisa. [...] Embora estes aspectos denominados de integridade na pesquisa digam respeito ao campo da ética, como horizonte norteador da conduta moral desejável do pesquisador científico, o que se convencionou chamar de Ética na Pesquisa abrange especificamente os procedimentos de proteção aos participantes de pesquisa diante dos riscos das pesquisas envolvendo seres humanos.

Observamos, na história das normativas éticas em pesquisas, que esta germina no campo das ciências biomédicas. Internacionalmente, podemos destacar o Código de Nuremberg, 
produzido em 1947 pelo Tribunal de Nuremberg, estabelecendo dez tópicos que os médicos devem seguir quando realizam experimentos em seres humanos, visando a dar subsídios para os julgamentos dos crimes contra a humanidade cometidos em pesquisas médicas conduzidas nos campos de concentração (SARDENBERG et al., 1999).

Acrescente-se também a Declaração de Helsinque, aprovada em assembleia da Associação Médica Mundial, em 1964, sendo ainda revisada em diversos momentos históricos, assim como as Diretrizes Internacionais Propostas para a Pesquisa Biomédica em Seres Humanos, elaboradas pela Organização Mundial da Saúde (OMS) e pelo Conselho de Organizações Internacionais de Ciências Médicas (COICIM) (CASTILHO; KALIL, 2005).

No Brasil, em 1988, há o surgimento do Código de Ética Médica Brasileiro e a Resolução no 01/1988, do Conselho Nacional de Saúde (CNS), que elenca princípios éticos em pesquisas médicas, mesclando aspectos éticos das pesquisas com questões referentes à biossegurança e à vigilância sanitária. Por meio da Resolução CNS no 196/1996 (BRASIL, 1996) foram definidas diretrizes e regulamentações de pesquisas cientificas, mas com perfil muito coadunado com as ciências médicas, área que protagonizou os estudos iniciais e de onde emanam tais diretrizes.

Esse cenário também pode ser explicado pelo campo das Ciências Humanas e Sociais (CHS) ainda passar por descredibilidade, não fruto dos resultados de suas pesquisas, mas ainda correlato à visão econômica e mercadológica do desenvolvimento da investigação científica. Tal cenário pode ser exemplificado, ademais, quando levamos em consideração as possibilidades de financiamentos das pesquisas, tendo as Ciências Biomédicas maiores fontes de recursos quando comparadas com as Ciências Humanas. É nítido ao vislumbrarmos parcerias de diversas empresas com universidades, propagando discursos de incentivo e desenvolvimento da Ciência no País, quando a real intenção seria o retorno para o mercado e a lucratividade que aquele investimento pode trazer, isto é, existem investimentos em determinadas áreas da Ciência que produzem resultados objetivos direcionados a uma aplicabilidade de lucro mercadológico (NOSELLA, 2008).

Posteriormente, surge a Resolução CNS no 466/2012 (BRASIL, 2012), notadamente marcada pelo luta da desvinculação das pesquisas em Ciências Humanas e Sociais das Ciências Biomédicas, dada à natureza dessas investigações. As particularidades das CHS, contudo, não foram atendidas. 
Nesse ínterim, a Associação Nacional de Pós-Graduação e Pesquisa em Educação (ANPEd), com apoio do Fórum de Coordenadores de Programas de Pós-Graduação em Educação (FORPREd), buscou construir alternativas a essa situação, ampliando a discussão sobre ética em pesquisa na área de Educação, participando do Grupo de Trabalho de CHS da Comissão Nacional de Ética em Pesquisa (CONEP) e criando, em 2015, uma Comissão de Ética em Pesquisa (FARE; MACHADO; CARVALHO, 2014; MAINARDES, 2017).

Mais recentemente, foram publicizadas normas restritas às pesquisas em Ciências Humanas e Sociais, por meio da Resolução CNS no 510/2016, cujos “[...] procedimentos metodológicos envolvam a utilização de dados diretamente obtidos com os participantes ou de informações identificáveis ou que possam acarretar riscos maiores do que os existentes na vida cotidiana [...]" (BRASIL, 2016).

Em face ao exposto, podemos observar que a preocupação ética com a pesquisa científica tem crescido no País. Instituições ligadas a esse campo produziram guias próprios, a fim de sensibilizar os pesquisadores para o tema da ética em pesquisa, como foi o caso do CNPq, por meio do Relatório da Comissão de Integridade de Pesquisa (BRASIL, 2011b), e da Fundação de Amparo à Pesquisa do Estado de São Paulo (FAPESP), com a publicação de um código de ética e conduta científica (SÃO PAULO, 2012, 2014), bem como a ampliação dos Comitês de Ética em Pesquisa (CEP) para analisar e dar parecer em projetos de pesquisa.

Segundo dados da Plataforma Brasil ${ }^{5}$, o País tem 845 CEP cadastrados, sendo 384 distribuídos pela região Sudeste, 172 no Nordeste, 154 na região Sul, 68 no Norte e 67 no CentroOeste. Destes, 39 cadastros estão alocados no Ceará, compreendendo os municípios de Aracati, Barbalha, Caucaia, Crato, Fortaleza, Juazeiro do Norte, Quixadá, Quixeramobim, Redenção e Sobral.

No Brasil, os CEP são aprovados e supervisionados pela Comissão Nacional de Ética em Pesquisa (CONEP). Têm composição multidisciplinar com participação de pesquisadores, estudiosos em ciências bioéticas, juristas, profissionais de diversas áreas (saúde, ciências sociais, humanas e exatas) e representantes da sociedade. São responsáveis pela revisão ética nos projetos de pesquisa submetidos, de modo a garantir e resguardar a integridade e os direitos dos

\footnotetext{
${ }^{5}$ Plataforma Brasil. Disponível em: http://aplicacao.saude.gov.br/plataformabrasil/login.jsf. Acesso em 15 mai. 2020.
} Periódico Horizontes - USF - Itatiba, SP - Brasil - e020051 
participantes das investigações (BRASIL, 2007).

Mesmo reconhecendo as limitações do atual aparato normativo sobre ética em pesquisa para a área de Ciências Humanas e Sociais no Brasil, e ciente da responsabilidade de também atender a quesitos éticos nesta pesquisa, a presente discussão fez emergir o seguinte problema: como os aspectos éticos das pesquisas são tratados em teses de doutorado em Educação?

Para tanto, neste artigo, objetivou-se analisar os aspectos éticos relacionados nas teses de doutorado de um Programa de Pós-Graduação em Educação de destaque, por apresentar nota 7, segundo a CAPES, instituição que regulamenta e avalia a pós-graduação brasileira. Tal análise discorre sobre diversas perspectivas que buscam estabelecer relações entre ética e produção do conhecimento, dando-se destaque às dimensões éticas correlatas à privacidade e ao sigilo na coleta de dados.

\section{Aspectos metodológicos}

Para atender ao problema de pesquisa, adotamos, como método de investigação, a pesquisa documental, descritiva e segundo uma abordagem mista. Caracteriza-se como pesquisa documental descritiva, pois sua função é descrever um fenômeno, determinando como ele é ou como se manifesta naquela conjuntura (ALVARENGA, 2012), em especial documentos primários de acesso público. Quanto à abordagem, trabalhamos com o que tem sido denominado de métodos mistos (mixed model research), também conhecido como multimétodos e triangulação. Isso implica na coleta e análise de dados qualitativos e quantitativos, de forma integrada, possibilitando inferências e maior entendimento do fenômeno estudado (JOHNSON; CHRISTENSEN, 2003; SAMPIERI; CALLADO; LUCIO, 2013).

O lócus da pesquisa é um dos Programas de Pós-Graduação em Educação (PPGE) no Brasil (seu nome não foi explicitado neste artigo, como já salientado, a fim de lhe preservar contra potenciais riscos e/ou desconfortos, em atenção ao cuidado ético necessário), possuidor de um estrato conceitual elevado (nota 7), segundo a CAPES, e que já contou com 804 dissertações e 203 teses de doutorado apresentadas até a presente investigação (julho/2017).

Serão discutidos os procedimentos éticos adotados em 92 teses de doutorado, resultantes de pesquisas em Educação no período de 2013 a 2016, com base na disponibilidade 
dessas produções no sítio virtual do Programa de Pós-Graduação. Segundo suas normativas legais, o Programa tem o objetivo de contribuir para a formação de pesquisadores e professores de excelência, altamente qualificados, reflexivos e conscientes de seu papel social, que possam contribuir para o aprimoramento teórico-metodológico na área educacional.

Para responder ao problema de pesquisa e, por conseguinte, ao objetivo expresso neste artigo, decidiu-se realizar um levantamento documental, que se caracteriza por buscas em fontes primárias, que ainda não receberam tratamento analítico em relação ao tema desta investigação (GIL, 1991). As 92 teses de doutorado foram consideradas documentos coletados (GARCIA; YASUDA; BENE, 2020) para serem submetidos à análise.

Os pontos analisados, balizados a partir do que Carvalho e Machado (2014) relacionam à ética na pesquisa, foram: o tipo de pesquisa, para averiguar, inicialmente, a necessidade de submissão a um Comitê de Ética; e o uso de seres humanos nas pesquisas. Em seguida, nos trabalhos que apresentam a participação de sujeitos, sondou-se a existência da descrição dos aspectos éticos utilizados, como a presença de termo de consentimento livre e esclarecido (TCLE) e se atende aos aspectos elencados pela Resolução CNS no 510/2016 (BRASIL, 2016).

Os dados qualitativos foram analisados de forma descritiva, enquanto os quantitativos foram analisados por meio da estatística descritiva, apresentando-os na forma de gráficos e tabelas, produzidos pelo GraphPadPrism7.

Quanto aos procedimentos éticos desta pesquisa, seguimos o preconizado pela Resolução no 510/2016 (BRASIL, 2016), no tocante à dispensa de registro no Sistema CEP/CONEP quando se trata de informações de acesso público, conforme dispõe a Lei $n^{\circ} 12.527$, de 18 de novembro de 2011 (BRASIL, 2011a). Ademais, tomamos o cuidado em garantir a privacidade, a confidencialidade e a segurança dos dados obtidos.

\section{Ética nas teses de doutorado: o que apontam os dados?}

O conjunto das 92 teses de doutorado, defendidas no recorte temporal selecionado (20132016), estão distribuídas em cada ano de publicação, de acordo com o Gráfico 1. Em média, obteve-se 23 teses por ano. O ano com o maior número de teses defendidas foi 2015, com 29 trabalhos apresentados, não havendo como precisar, contudo, o motivo para esse destaque. 
Gráfico 1 - Frequência absoluta, por ano, de teses de doutorado defendidas em um Programa de Pós-graduação em Educação

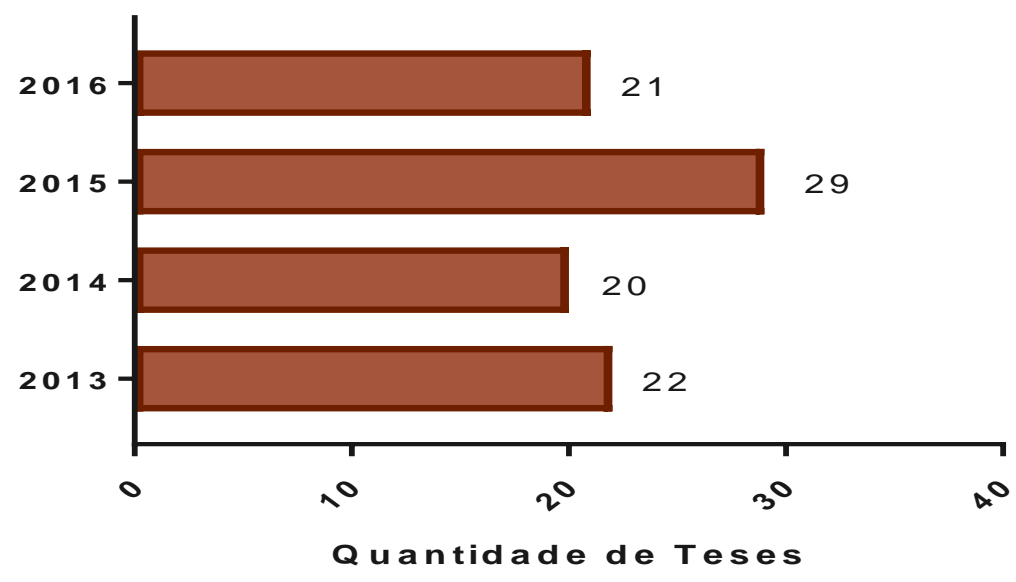

Fonte: Elaborado pelos autores

Segundo o Banco de Teses e Dissertações da CAPES ${ }^{6}$, no Brasil, de 2013 a 2020, foram defendidos 144.026 trabalhos de conclusão de doutorado, sendo 8.630 na área de Educação. Destes, a maior parte está centrada na região Sudeste do País, concentrando $48,3 \%$ das publicações, seguida pelas regiões Sul (23,3\%), Nordeste $(18,0 \%)$, Centro Oeste $(8,2 \%)$ e Norte, que possui menor expressão, com apenas 2,2\% (BRASIL, 2020).

Com base no art. 1ㅇ da Resolução CNS no 510/2016 (BRASIL, 2016), buscou-se quantificar as teses publicadas que trabalharam diretamente com seres humanos e que não se encaixam nas exceções do parágrafo único do referido artigo, as quais necessitam ser registradas em um Comitê de Ética em Pesquisa. Na análise realizada, observamos que 32 trabalhos (34,8\% do total) se encaixam nesse critério (Gráfico 2). As demais 60 teses são fruto de pesquisas de cunho mais teórico ou que se utilizaram de dados de acesso ou domínio público.

Dessas 32 teses, $25 \%$ (8) informam que os projetos de pesquisa foram submetidos e aprovados por um Comitê de Ética. Outros trabalhos que não se submeteram a um CEP, no entanto, incluem, em seus anexos ou apêndices, um TCLE e/ou um termo de anuência do local pesquisado.

\footnotetext{
${ }^{6}$ Dados apresentados de acordo com o Painel de Informações Quantitativas (teses e dissertações)/CAPES. Disponível em: https://bit.ly/3ax5PhH. Acesso em: 25 abr. 2020.
} 
Gráfico 2 - Distribuição percentual das teses de doutorado que envolvem seres humanos.

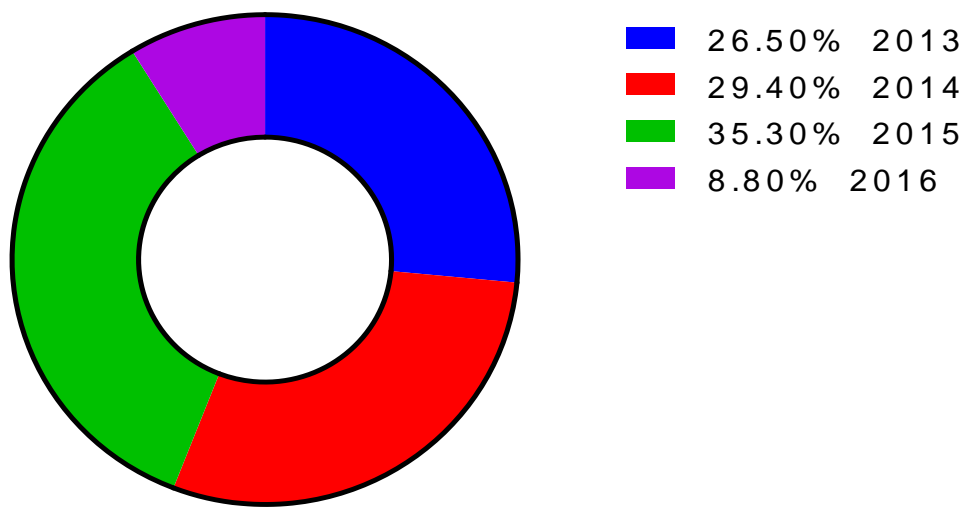

Fonte: Elaborado pelos autores

Tenório et al. (2005) apontam que, em uma investigação sobre os preceitos éticos em um periódico brasileiro, de 71 artigos publicados, apenas em dois havia menção à garantia de anonimato das informações fornecidas pelos sujeitos e/ou de seus dados biológicos relativos. Apenas cinco descreviam que o TCLE havia sido solicitado aos sujeitos da pesquisa; contudo, somente dois continham expressamente a referência à aprovação do estudo por um CEP.

Buscamos verificar, por conseguinte, se aspectos éticos são citados e quais são considerados nas pesquisas analisadas. Diante disso, delineamos, na Tabela 1, alguns pontos que acreditamos ser de relevância e pertinentes para nossa análise. As questões propostas buscaram contemplar a apresentação de algumas categorias das dimensões éticas de pesquisa, que seriam principalmente: TCLE e submissão a Comitê de Ética, independente do enfoque teórico.

Tabela 1 - Quantificação de teses que envolvem sujeitos humanos e que apresentam ou não TCLE / Comitê de Ética do Programa de Pós-Graduação, 2013-2016

\begin{tabular}{|c|c|c|c|c|c|}
\hline Aspectos & 2013 & 2014 & 2015 & 2016 & TOTAL \\
\hline Envolvem sujeitos humanos & 7 & 8 & 10 & 7 & 32 \\
\hline Apresentam TCLE & 2 & 2 & 2 & 2 & 8 \\
\hline Apresentam comprovação de submissão a CEP & 2 & - & - & - & 2 \\
\hline $\begin{array}{l}\text { Apresentam tanto TCLE, quanto comprovação de } \\
\text { submissão a CEP }\end{array}$ & 1 & - & - & - & 1 \\
\hline Apresentam apenas carta de apresentação & - & 1 & - & - & 1 \\
\hline $\begin{array}{l}\text { No corpo texto dizem ter TCLE, mas não está } \\
\text { anexo }\end{array}$ & - & 1 & - & 1 & 2 \\
\hline
\end{tabular}

Fonte: Elaborado pelos autores. 
É válido salientar que, das 32 teses identificadas que envolvem sujeitos humanos, duas não apresentam texto disponível no sítio público do Programa. Um desses trabalhos traz, inclusive, resumo correto; contudo, o arquivo PDF acessível é de outra tese, impedindo, nesse caso, análise adequada, fato que também foi recorrente quando se fez a busca pelo texto no Catálogo de Teses e Dissertações da CAPES.

Observou-se que, em teses de doutorado classificadas como estudo de caso e/ou pesquisa etnográfica, defendidas perante banca de avaliação, aprovadas e, a posteriori, publicadas, houve utilização de imagens e falas de entrevistados, até mesmo de crianças e adolescentes, revelando-se nomes e identificando-se participantes. Além disso, não apresentam TCLE, pedido de autorização (mesmo naquelas que envolvem instituições públicas), nem autorização de representantes/autoridades diretas, algo eticamente grave.

Segundo o art. 16, da Sessão II, da Resolução CNS no 510/2016, com relação à possibilidade de não aplicação de TCLE:

Art. 16. O pesquisador deverá justificar o meio de registro mais adequado, considerando, para isso, o grau de risco envolvido, as características do processo da pesquisa e do participante.

$\S 1$ 을 Os casos em que seja inviável o Registro de Consentimento ou do Assentimento Livre e Esclarecido ou em que este registro signifique riscos substanciais à privacidade e confidencialidade dos dados do participante ou aos vínculos de confiança entre pesquisador e pesquisado, a dispensa deve ser justificada pelo pesquisador responsável ao sistema CEP/CONEP.

$\S 2$ o A dispensa do registro de consentimento ou de assentimento não isenta o pesquisador do processo de consentimento ou de assentimento, salvo nos casos previstos nesta Resolução.

$\S$ 3ㅇ A dispensa do Registro do Consentimento deverá ser avaliada e aprovada pelo sistema CEP/CONEP (BRASIL, 2016, p.7).

Partindo dessa regulamentação, agrava-se a preocupação frente às investigações científicas que não estão propondo-se minimamente a seguir procedimentos éticos exigidos a tais pesquisas. Acrescente-se o fato de que essa Resolução também possibilita conhecer o ônus dessa situação, quando descreve as possibilidades de consequências/danos que poderão vir a sofrer tanto os participantes quanto o pesquisador.

Baseando-nos no Capítulo VI, ainda da Resolução CNS no 510/2016 (BRASIL, 2016), a responsabilidade do pesquisador é indelegável e indeclinável, compreendendo aspectos éticos e 
legais, isto é, dado qualquer possível dano legítimo a participantes ou que esses aleguem ter possivelmente sofrido, o pesquisador está passível de responder, inclusive judicialmente.

Retomando a análise das teses que apresentam TCLE, temos algumas indagações correlatas à própria constituição do Termo, quando este não apresenta todos os pontos necessários em relação a esclarecimentos, assentimentos e consentimentos por parte dos participantes e público assistido. Também requer atenção a existência ou não de documento complementar, regulado e previsto pela referida Resolução (BRASIL, 2016),

Para os fins da Resolução CNS no 510/2016, o TCLE deve apresentar: anuência e assistência do/ao participante; esclarecimento acerca de benefícios, confidencialidade e consentimento sobre o quê e de quem, se as informações serão publicizadas e se poderá ocorrer algum dano material ou imaterial; explicitação de que se propõe livre de qualquer referência a discriminação, preconceito ou estigmatização; compromisso com a apresentação de esclarecimentos em todas as etapas da pesquisa e sempre que solicitado pelos participantes; tipo de pesquisa; informação sobre o que é TCLE e CEP; funções, responsabilidades e contatos do pesquisador; contatos do(s) órgão(s) responsável(is) pela revisão ética do projeto de pesquisa; vulnerabilidade e riscos da investigação; e ressarcimentos mediante comprovação de possíveis danos (BRASIL, 2016).

Na Tabela 2, é alarmante que apenas oito trabalhos científicos tragam TCLE e/ou parecer de Comitê de Ética. Destes, somente um contempla totalmente, em seu texto, os pré-requisitos exigidos na regulamentação. Metade dos trabalhos, apesar de chamar de TCLE, apresentam, apenas brevemente, o que se poderia classificar como uma Carta de Apresentação, seja do pesquisador e/ou da pesquisa, pois não traz informações sobre o pesquisador nem esclarecem minimamente os possíveis riscos, mesmo utilizando imagens dos participantes. O restante das publicações até produziram termo, autorização, documento complementar ao TCLE apresentado; contudo, nem com essa complementação, há o preenchimento de todos os requisitos éticos de aplicação do Termo junto aos participantes envolvidos. 
Tabela 2 - Características do TCLE e dimensões éticas que devem estar previstas em sua constituição, junto às teses analisadas do Programa de Pós-Graduação, 2013-2016

\begin{tabular}{|c|c|c|c|c|c|}
\hline Aspectos & 2013 & 2014 & 2015 & 2016 & TOTAL \\
\hline Apresenta o TCLE & 2 & 2 & 2 & 2 & 8 \\
\hline $\begin{array}{l}\text { TCLE completo (contempla todos os requisitos } \\
\text { exigidos pela Resolução CNS no 510/2016, em um } \\
\text { único documento) }\end{array}$ & 1 & - & - & - & 1 \\
\hline $\begin{array}{l}\text { TCLE apenas COMO uma carta de apresentação, } \\
\text { sem contemplar minimamente os pré-requisitos } \\
\text { necessários à sua constituição válida, e sem } \\
\text { documento complementar }\end{array}$ & 0 & 1 & 1 & 2 & 4 \\
\hline $\begin{array}{l}\text { Possui termo/documento complementar ao seu } \\
\text { texto, conforme previsto em norma para devidos } \\
\text { esclarecimentos e complementações, mas sem } \\
\text { contemplar todas as dimensões éticas }\end{array}$ & 1 & 1 & 1 & - & 3 \\
\hline
\end{tabular}

Fonte: Elaborado pelos autores.

O TCLE é um dos mais importantes documentos que devem estar presentes em uma pesquisa científica. Nele são relatadas todas as etapas do procedimento, seus benefícios e riscos, bem como vantagens, desvantagens e limitações, devendo ser lido e assinado pelo participante da pesquisa, dando ciência de sua participação voluntária (SOUZA et al., 2013). O documento precisa ser elaborado, ademais, em uma linguagem e vocabulário acessível, sem o uso de termos técnicos e siglas, o qual impeça o entendimento do sujeito, além de conter frases e parágrafos curtos (GODINHO; LANZIOTTI; MORAIS, 2010; MIRANDA et al., 2009).

\section{Considerações finais}

A discussão sobre ética é atual, válida e necessária para a produção científica de forma geral. É preciso se preocupar como ela está sendo empregada no âmbito da investigação científica. Nesse intuito, buscou-se a possibilidade de esclarecer o que se compreende como ética, sua relação com a produção de conhecimento no Brasil e nas produções da área de Ciências Humanas e Sociais, enfocando o campo da Educação.

No contexto da educação superior brasileira, temos complexo conflito no desenvolvimento científico e tecnológico em relação à questão ética, na medida em que a visão 
preponderante ainda é uma educação para o mercado e, fruto disto, talvez menos ética e formativa. Ainda não se conseguiu saber como compor, harmonizar esses objetivos, principalmente, quando se fala de Educação, pois sua constituição teórica está assentada em sua função social, humana, formativa e integral (SEVERINO, 2014).

Importante destacar, contudo, que os trabalhos analisados aqui são teses de doutorado apresentadas por um Programa que fora avaliado com o conceito máximo, pela instituição responsável pela regulamentação desses cursos, sendo assim referência da produção de pesquisa científica. Deveria ser um dos loci norteadores de procedimentos e esclarecimentos sobre dimensões éticas de modo geral e, principalmente, em pesquisas científicas da área de Educação no Brasil. Essa situação sugere, por conseguinte, que deveria haver preocupação da CAPES na criação de critérios de avaliação que contemplem os aspectos éticos em dissertações e teses no País.

Os resultados obtidos levam a inferir sobre a necessidade de investigações que se debrucem acerca da ética em pesquisa, particularmente na área da Educação. Além disso, permitem vislumbrar seu potencial de contribuição para uma reanálise de como se está trabalhando a ética na pesquisa científica da área de Educação, no Brasil, de acordo com suas peculiaridades. A análise realizada aponta um quadro que põe em evidência insuficiências e a necessidade urgente de desenvolvimento de um olhar mais comprometido com a formação ética dos pesquisadores, conforme assinalam outros estudos (NUNES, 2016, 2017), para além de se conhecer as normas que se propõem a regulamentar a ética em pesquisas.

\section{Referências}

ALVARENGA, E. M. Metodologia da investigação quantitativa e qualitativa. Assunção: Gráfica Saf, 2012.

BRASIL. Ministério da Saúde. Conselho Nacional de Saúde (CNS). Resolução no 196/1996, de 10 de outubro de 1996. Brasília, DF, 1996. Disponível em:

http://bvsms.saude.gov.br/bvs/saudelegis/cns/1996/res0196_10_10_1996.html. Acesso em: 06 jul. 2017.

BRASIL. Conselho Nacional de Saúde. Atribuições do CEP-CONEP.2007. Disponível em: http://conselho.saude.gov.br/web_comissoes/conep/aquivos/conep/atribuicoes.html. Acesso em: 06 jul. 2017. 
BRASIL. Casa Civil. Subchefia para Assuntos. Lei no 12.527, de 18 de novembro de 2011a. Regula o acesso a informações previsto no inciso XXXIII do art. 5ํ, no inciso II do § 3잉 do art. 37 e no § 2ㅇ do art. 216 da Constituição Federal. Diário Oficial da União, Brasília, DF, 18 nov.2011a. Disponível em: http://www.planalto.gov.br/ccivil 03/ ato20112014/2011/lei/l12527.htm. Acesso em: 06 jul. 2017.

BRASIL. Conselho Nacional de Desenvolvimento Científico e Tecnológico (CNPq). Relatório da Comissão de Integridade de Pesquisa do CNPq. Brasília, DF, 2011b. Disponível em: http://www.cnpq.br/documents/10157/a8927840-2b8f-43b9-8962-5a2ccfa74dda. Acesso em: 06 jul. 2017.

BRASIL. Ministério da Saúde. Conselho Nacional de Saúde (CNS). Resolução no 466/2012, de 12 de dezembro de 2012. Brasília, DF, 2012. Disponível em: http://conselho.saude.gov.br/resolucoes/2012/Reso466.pdf. Acesso em: 06 jul. 2017.

BRASIL. Ministério da Saúde. Conselho Nacional de Saúde (CNS). Resolução no 510/2016, de 7 de abril de 2016. Brasília, 2016. Disponível em: http://conselho.saude.gov.br/resolucoes/2016/Reso510.pdf. Acesso em: 06 jul. 2017.

BRASIL. CAPES. Teses e dissertações defendidas no Brasil, quantificadas por grande área e área do conhecimento, IES, classificados por grande, UF e ano. 2020. Disponível em:

http://analisevisual.capes.gov.br/SASVisualAnalyticsViewer/VisualAnalyticsViewer_guest.jsp?re portName=Banco+de+Teses+e+Disserta\%C3\%A7\%C3\%B5es+-

+Informa\%C3\%A7\%C3\%B5es+quantitativas\&reportPath=/DTI/Banco_de_teses_e_dissertacoes/ Relatorios\&reportViewOnly=false\&appSwitcherDisabled=true. Acesso em: 15 mai. 2020.

CARVALHO, I. C. M.; MACHADO, F. V. A regulação da pesquisa e o campo biomédico: considerações sobre um embate epistêmico desde o campo da educação. Práxis Educativa, v.9, n.1, p.209-34, 2014.

CASTILHO, E. A.; KALIL, J. Ética e pesquisa médica: princípios, diretrizes e regulamentações. Rev Soc Bras Med Trop, v.38, n.4, p.344-347, 2005.

CUNHA, L. A. A universidade temporã: da colônia à era de Vargas. 2. ed. Rio de Janeiro: Livraria Francisco Alves, 1986.

FARE, M.; MACHADO, F.; CARVALHO, I. Breve revisão sobre regulação da ética em pesquisa: subsídios para pensar a pesquisa em educação no Brasil. Práxis Educativa, v.9, n.1, p.247-283, 2014.

GARCIA, F. M.; YASUDA, B. C.; BENE, L. E. Observações preliminares acerca das pesquisas em educação do Amazonas. Educação \& Formação, v.5, n.14, p.36-53, 2020. 
GIL, A. C. Métodos e técnicas de pesquisa social. 3. ed. São Paulo: Atlas, 1991.

GODINHO, A. M.; LANZIOTTI, L. H.; MORAIS, B. S. Termo de consentimento informado: a visão dos advogados e tribunais. Rev Bras Anestesiol, v.60, n.2, p.207-211, 2010.

GOERGEN, P. L. A ética em pesquisa. Práxis Educativa, v.10, n.2, p.301-315, 2015.

JOHNSON, B.; CHRISTENSEN, L. B. Educational research: quantitative, qualitative and mixed approaches. 2. ed. Boston: Allyn \& Bacon.2003.

MAINARDES, J. A ética na pesquisa em educação: panorama e desafios pós-Resolução CNS no 510/2016. Educação, Porto Alegre, v.40, n.2, p.160-173, 2017.

MIRANDA, V. C.; FEDE, A. B. S.; LERA, A. T.; UEDE, A.; ANTONAGELO, D. V.; BRUNETTI, K.; RIECHELMANN, R.; GIGLIO, A. Como consentir sem entender? Rev Assoc Med Bras, v.55, n.3, p.328-334, 2009.

NOSELLA, P. Ética e pesquisa. Educação \& Sociedade, v.29, n.102, p.255-273, 2008.

NUNES, J. B. C. Formação de pesquisadores em educação para a ética em pesquisa. In: CARVALHO, M. V. C.; CARVALHÊDO, J. L. P.; ARAUJO, F. A. M. Caminhos da Pós-Graduação em Educação no Nordeste do Brasil: avaliação, financiamento, redes e produção científica. Teresina: EDUFPI, 2016. p.59-71.

NUNES, J. B. C. Formação para a ética em pesquisa: um olhar para os programas de pósgraduação em Educação. Educação, Porto Alegre, v.40, n.2, p.183-191, 2017.

OLIVEIRA, J. F.; FONSECA, M. A pós-graduação brasileira e o seu sistema de avaliação. In: OLIVEIRA, J. F.; CATANI, A. M.; FERREIRA, N. S. C. Pós-Graduação e avaliação: impactos e perspectivas no Brasil e no cenário internacional. Campinas: Mercado de Letras, 2010. p.15-51.

SAMPIERI, R. H.; CALLADO, C. F.; LUCIO, M. P. B. Metodologia da pesquisa. 5. ed. Porto Alegre: Penso, 2013.

SÃO PAULO. Fundação de Amparo à Pesquisa do Estado de São Paulo (Fapesp). Código de boas práticas científicas. São Paulo, 2012. Disponível em:

https://www.unip.br/pesquisa/download/FAPESP_Codigo_de_Boas_Praticas_Cientificas_jun20 12.pdf. Acesso em: 06 jul. 2017.

SÃO PAULO. Fundação de Amparo à Pesquisa do Estado de São Paulo (Fapesp). Código de boas práticas científicas. São Paulo, 2014. Disponível em:

http://www.fapesp.br/boaspraticas/FAPESP-Codigo_de_Boas_Praticas_Cientificas_2014.pdf. Acesso em: 06 jul. 2017.

SARDENBERG, T; MULLER, S. S.; PEREIRA, H. R.; OLIVEIRA, R. A.; HOSSNE, W. S. Análise dos 
aspectos éticos da pesquisa em seres humanos contidos nas Instruções aos Autores de 139 revistas científicas brasileiras. Revista da Associação Médica Brasileira, v.45, n.4, p.295-302, 1999.

SEVERINO, A. J. Dimensão ética da investigação científica. Práxis Educativa, v.9, n.1, p.199-208, 2014.

SOUZA, M. K.; JACOB, C. E.; GAMA-RODRIGUES, J.; ZILBERSTEIN, B.; CECCONELLO, I.; HABRGAMA, A. Termo de consentimento livre e esclarecido (TCLE): fatores que interferem na adesão. ABCD. Arquivos Brasileiros de Cirurgia Digestiva, São Paulo, v.26, n.3, p.200-205, 2013.

TENÓRIO, M. C. M.; BEZERRA, J.; TASSITANO, R. M.; BARROS, M. V. G.; COSTA, A. M. Ética na pesquisa com seres humanos: revisão dos artigos publicados na Revista Paulista de Educação Física (1996-2004). Revista Brasileira de Educação Física e Esporte, v.19, n.4, p.329-335, 2005.

VEATCH, R. M. Bioética. 3. ed. São Paulo: Pearson, 2014.

Recebido em maio 2019.

Aprovado em julho 2020 